\title{
Intracranial pressure-based barbiturate coma treatment in children with refractory intracranial hypertension due to traumatic brain injury
}

\author{
Fartein Velle, MD, Anders Lewén, MD, PhD, Timothy Howells, PhD, Per Enblad, MD, PhD, and \\ Pelle Nilsson, MD, PhD
}

Section of Neurosurgery, Department of Neuroscience, Uppsala University, Uppsala, Sweden

\begin{abstract}
OBJECTIVE Refractory intracranial pressure (ICP) hypertension following traumatic brain injury (TBI) is a severe condition that requires potentially harmful treatment strategies such as barbiturate coma. However, the use of barbiturates may be restricted due to concerns about inducing multiorgan system complications related to the therapy. The purpose of this study was to evaluate the outcome and occurrence of treatment-related complications to barbiturate coma treatment in children with refractory intracranial hypertension (RICH) due to TBI in a modern multimodality neurointensive care unit (NICU).
\end{abstract}

METHODS The authors conducted a retrospective cohort study of 21 children $\leq 16$ years old who were treated in their NICU between 2005 and 2015 with barbiturate coma for RICH following TBI. Demographic and clinical data were acquired from patient records and physiological data from digital monitoring system files.

RESULTS The median age of these 21 children was 14 years (range 2-16 years) and at admission the median Glasgow Coma Scale score was 7 (range 4-8). Barbiturate coma treatment was added due to $\mathrm{RICH}$ at a median of 46 hours from trauma and had a median duration of 107 hours. The onset of barbiturate coma resulted in lower ICP values, lower pulse amplitudes on the ICP curve, and decreased amount of A-waves. No major disturbances in blood gases, liver and kidney function, or secondary insults were observed during this period. Outcome 1 year later revealed a median Glasgow Outcome Scale score of 5 (good recovery), however on the King's Outcome Scale for Childhood Head Injury, the median was $4 a$ (moderate disability).

CONCLUSIONS The results of this study indicate that barbiturate coma, when used in a modern NICU, is an effective means of lowering ICP without causing concomitant severe side effects in children with $\mathrm{RICH}$ and was compatible with good long-term outcome.

https://thejns.org/doi/abs/10.3171/2019.10.PEDS19268

KEYWORDS traumatic brain injury; barbiturate coma; refractory intracranial hypertension; outcome; trauma

$\mathrm{T}$ RAUMATIC brain injury (TBI) in childhood is a common cause of death and acquired disability in the developed world and even more so in less-developed parts of the world. According to recent publications, the estimated annual median incidence of childhood TBI in North America, Europe, Australia, and New Zealand is 691 per 100,000 people treated in emergency departments; 74 per 100,000 are hospitalized, and 9 per 100,000 result in death. ${ }^{38}$ According to the Swedish National Board of Health and Welfare, ${ }^{36}$ the total death rate in Sweden in the age group of $1-14$ years is $8 / 100,000$ per year. Trauma deaths account for $1 / 100,000$ per year in the same patient group, but was twice as high a decade earlier (http:// nowbase.org/). ${ }^{35,36}$ Of Sweden's 1.9 million children (0-17 years old) in 2014, approximately 18,300 children were hospitalized due to trauma and 3600 of these admissions were due to TBI. ${ }^{36}$ During 2014, 160/100,000 children in Sweden 0-14 years of age were diagnosed with intracranial injury and 5.4/100,000 required cranial surgery that was related to the trauma. ${ }^{36}$

ABBREVIATIONS $\mathrm{CPP}=$ cerebral perfusion pressure; $\mathrm{CVP}=$ central venous pressure; $\mathrm{EVD}=$ external ventricular drain; $\mathrm{GCS}=\mathrm{Glasgow}$ Coma Scale; $\mathrm{GMT}=$ good monitoring time; $\mathrm{GOS}=$ Glasgow Outcome Scale; ICP = intracranial pressure; $\mathrm{KOSCHI}=$ King's Outcome Scale for Childhood Head Injury; MAP = mean arterial pressure; $\mathrm{MVO}=$ motor vehicle occupant; $\mathrm{NICU}=$ neurointensive care unit; $\mathrm{pCO}_{2}=$ partial pressure of carbon dioxide; $\mathrm{RICH}=$ refractory intracranial hypertension; $\mathrm{TBI}$ = traumatic brain injury.

SUBMITTED May 7, 2019. ACCEPTED October 8, 2019.

INCLUDE WHEN CITING Published online December 27, 2019; DOI: 10.3171/2019.10.PEDS19268. 
Children with moderate to severe TBI require advanced neurointensive care to minimize secondary brain injury. Despite first-tier therapy focused on prevention of secondary insults and surgical evacuation of mass lesions, some patients still develop refractory intracranial hypertension (RICH). In many neurointensive care units (NICUs), $\mathrm{RICH}$ is treated with barbiturate coma. Barbiturate coma treatment in adults is well established, 9,17,20,21,28 but many neurosurgical centers have a more restrictive attitude toward this treatment in children. ${ }^{24,37}$ The reasons for this include unclear outcome results and risk of adverse events related to the toxic effects of barbiturates. ${ }^{15,20,31,32}$ Only one article has so far been published covering this topic, ${ }^{22}$ which is the only new reference directly addressing this topic added to the chapter content on barbiturate coma treatment of the third edition of Brain Trauma Foundation Guidelines for the Management of Pediatric Severe Traumatic Brain Injury. ${ }^{16}$ There also exists uncertainty concerning the most appropriate barbiturate to use..$^{8,26}$ Experimental research has demonstrated that the level of neuroprotection attained by the various barbiturates is not equal. ${ }^{2,4,26,35}$ In a prospective randomized Spanish cohort of 44 patients in 2008, thiopental appeared to be more effective than pentobarbital in controlling $\mathrm{RICH} .{ }^{26}$ More knowledge concerning different aspects of barbiturate coma treatment in children is needed.

The aim of this study was to determine the outcome and occurrence of side effects/complications when barbiturate treatment (thiopental) was used in children with RICH in a modern intensive care unit setting with structured care and advanced multimodality monitoring with digitized acquisition systems.

\section{Methods \\ Study Population}

Uppsala University Hospital is a level 1 trauma center serving the middle part of Sweden with a population of 2 million people. In addition to all neurosurgical cases admitted to the department, all severe neurotrauma cases in both adults and children are admitted to the NICU from 24 local hospitals located within a distance of approximately $300 \mathrm{~km}$.

During a 10-year period (2005-2015), 60 children $\leq 16$ years of age, with severe TBI and a Glasgow Coma Scale (GCS) score $\leq 8$ (GCS motor score $\leq 5$ ), who were intubated and had received an intracranial pressure (ICP) monitor, were treated at the NICU. Twenty-one of these patients developed RICH despite surgical evacuation of mass lesions or hemicraniectomy and had barbiturates added to their treatment. These patients were included in this retrospective study. Demographic data and clinical information were retrieved from patient records. Physiological minuteby-minute data were retrieved from our database of digital monitoring system recordings.

This study was approved by Uppsala University's ethical committee. Informed consent was not required.

\section{Study Variables}

The following variables were studied: cause of injury; time from trauma to NICU; neurological status according to GCS score at admittance to the NICU and at departure; Rotterdam CT score of initial brain CT scan; ${ }^{18,19}$ start and length of barbiturate coma treatment; serum thiopental concentrations; dose of thiopental; side effects observed during barbiturate coma (infections, hepatocellular toxicity, and renal dysfunction); and deviations from goals. A Glasgow Outcome Scale (GOS) ${ }^{14}$ score and a more specific estimated King's Outcome Scale for Childhood Head Injury (KOSCHI) score was determined at 1 year based on information from patient rehabilitation records. ${ }^{3,6,25}$

\section{NICU Procedures and Patient Management}

Uppsala has a dedicated NICU with standardized treatment protocol-based organization and a specific focus on identifying and treating secondary insults. ${ }^{10}$ All levels of staff have specified roles for achieving the goals in the unit's protocols (Table 1). The Odin monitoring system ${ }^{13}$ is used for collection and visualization of all monitoring data bedside (minute and high resolution). All documentation is recorded in an electronic patient management system. Specific interfaces have been created for daily rounds and the end of nurses' shifts, where results of treatment goals over the shift are evaluated and recorded. ${ }^{23}$

Neurological state (GCS motor score) is assessed regularly by wakeup tests if the patient has stable ICP. All admitted patients not responding to commands (GCS motor score $\leq 5$ ) are routinely intubated, and in the acute phase mild hyperventilation partial pressure of carbon dioxide $\left(\mathrm{pCO}_{2}\right)$ at $30-34 \mathrm{~mm} \mathrm{Hg}(4-4.5 \mathrm{kPa})$ is applied until ICP monitoring is in place. All patients with GCS motor scores $\leq 5$ receive an ICP monitor, preferably an external ventricular drain (EVD).

Sedation is maintained with infusions of propofol at first, but in children it is replaced by midazolam and morphine as soon as they are stable. The primary aim is that the patients are normovolemic with adequate colloid osmotic pressure. Sodium concentrations are kept around $140 \mathrm{mmol} / \mathrm{L}$ and a zero or slightly negative water balance. Central venous pressure (CVP) is maintained at $0-5 \mathrm{~mm}$ Hg. Albumin (20\%) infusions are used to maintain intravascular colloid osmotic pressure. Noradrenaline or dobutamine infusions are administered if hypotension occurs.

The neurointensive care management in Uppsala is ICP oriented and not primarily cerebral perfusion pressure (CPP) oriented. The goal is to keep ICP $<20 \mathrm{~mm} \mathrm{Hg}$ and CPP around $60 \mathrm{~mm} \mathrm{Hg}$ in adults and as low as 45-50 $\mathrm{mm} \mathrm{Hg}$ is accepted in children depending on age. During barbiturate coma, CPP levels down to $50 \mathrm{~mm} \mathrm{Hg}$ are accepted in adults and $40-45 \mathrm{~mm} \mathrm{Hg}$ in children. In cases of high ICP, no attempt is made in general to actively increase CPP above $60 \mathrm{~mm} \mathrm{Hg}$ by increasing blood pressure above normal levels, but spontaneous CPP levels over 60 $\mathrm{mm} \mathrm{Hg}$ are not actively lowered unless the raised CPP has a detrimental effect on ICP levels. The aim of this strategy is to prevent the development of secondary brain edema in tissue with a disturbed blood-brain barrier and/or cerebral vascular autoregulation..$^{11,12}$

If ICP increases despite this basal therapy, a reevaluation of the occurrence of secondary insults is conducted and a new CT scan is performed to rule out surgical mass lesions before escalation of ICP therapy to step 1 . This es- 
TABLE 1. Uppsala NICU treatment goals in children

\begin{tabular}{ll}
\hline \multicolumn{1}{c}{ Variable } & \multicolumn{1}{c}{ Goal (depending on age) } \\
\hline $\mathrm{ICP}$ & $<20 \mathrm{~mm} \mathrm{Hg}$ \\
\hline $\mathrm{CPP}$ & $45-60 \mathrm{~mm} \mathrm{Hg}(40-50 \mathrm{in} \mathrm{BC})$ \\
\hline $\mathrm{BPsyst}$ & $>80-100 \mathrm{~mm} \mathrm{Hg}$ \\
\hline $\mathrm{CVP}$ & $0-5 \mathrm{~mm} \mathrm{Hg}$ \\
\hline $\mathrm{pCO}_{2}$ & $30-34 \mathrm{~mm} \mathrm{Hg}(4.0-4.5 \mathrm{kPa}$; normoventilation ASAP $)$ \\
\hline $\mathrm{pO}_{2}$ & $>90 \mathrm{~mm} \mathrm{Hg}(>12 \mathrm{kPa})$ \\
\hline $\mathrm{SaO}_{2}$ & $>96 \%$ \\
\hline $\mathrm{B}-\mathrm{glucose}$ & $5-10 \mathrm{mmol} / \mathrm{L}$ \\
\hline Temperature & Normothermia $<38^{\circ} \mathrm{C}$ \\
\hline $\mathrm{Hb}$ & $>100 \mathrm{~g} / \mathrm{L}$ \\
\hline Electrolytes & Normal references $(\mathrm{K}>2.3 \mathrm{mmol} / \mathrm{L}$ in $\mathrm{BC})$ \\
\hline Water balance & Normovolemic to slightly negative \\
\hline
\end{tabular}

ASAP = as soon as possible; $\mathrm{BC}=$ barbiturate coma; $\mathrm{BPsyst}=$ systolic blood pressure; $\mathrm{Hb}=$ hemoglobin; $\mathrm{K}=$ potassium; $\mathrm{pO}_{2}=$ partial pressure of oxygen; $\mathrm{SaO}_{2}=$ oxygen saturation.

calated therapy includes: deeper sedation with midazolam and morphine; stress reduction with beta-blockers in the form of metoprolol and centrally acting alpha-adrenoceptor stimulators (clonidine); and intermittent drainage of CSF from an EVD if possible. If there is no radiological sign of development of expanding mass lesions, the intermittent drainage of CSF can, after some time (1-2 days), be changed to continuous drainage against a pressure level of $15-20 \mathrm{~mm} \mathrm{Hg}$.

If these measures do not alleviate ICP problems, step 2 therapy is initiated. A new reevaluation of all parameters is performed and if cerebral CT shows no significant mass lesion or midline shift, a barbiturate coma is initiated. Osmotherapy is not included in the protocol. Midazolam infusion is changed to thiopental infusion as a monosedative (pentocur, Abcur AB) in the lowest dose needed to decrease ICP. Burst suppression on EEG is not a primary goal. Barbiturate coma is initiated with thiopental bolus doses (total $8-10 \mathrm{mg} / \mathrm{kg}$ in adults and $3-5 \mathrm{mg} / \mathrm{kg}$ in children) given as small repeated doses (50-mg doses in adults and between 10 and $50 \mathrm{mg}$ doses in children depending on weight) until ICP normalizes. Intermittent doses are given to ensure that there is minimal effect on mean arterial blood pressure. A continuous infusion of thiopental is started at the same time as the boluses are given (initial dose $5-10 \mathrm{mg} / \mathrm{kg} / \mathrm{hr}$ ), which is adjusted over time depending on ICP levels, suppression periods on EEG, and serum concentrations of thiopental. The EEG monitoring is primarily used to observe and prevent excessive thiopental doses causing excessively long periods of suppression and to monitor for seizures. Serum thiopental levels less than $300 \mu \mathrm{mol} / \mathrm{L}$ are the preferred primary serum concentration levels. This strategy using the lowest possible dose of thiopental to decrease ICP is intended to minimize the risk of medication-related complications. ${ }^{11}$ Patients receive only parenteral nutrition during barbiturate coma treatment. Patients are kept on thiopental as short a time as possible depending on clinical status, interpretation of intracranial dynamics (mean ICP, amplitude, and plateau waves), CT brain findings, and severity of complications. If ICP cannot be controlled in this way, a decompressive craniectomy is performed.

\section{Results \\ Patient Characteristics}

The median age of the 21 children was 14 years (range 2-16 years); there were 12 boys and 9 girls, with a median weight of $58 \mathrm{~kg}$ (range 12-82 kg). The causes of injury were motor vehicle occupant (MVO; $n=5)$, pedestrian hit by car $(n=6)$, bicycle accidents $(n=4)$, and sport/play related $(n=6)$. At NICU admission the median GCS score was 7 (range 4-8) and GCS motor score was 5 (range 2-5). Nine of the children had fixed dilated pupils at admission, 3 bilateral and 6 unilateral, of whom 3 had orbital facial fractures. Seven children showed focal motor deficits at admission. On the first CT scan of the brain the median Rotterdam CT score was 4 (range 4-5). The average time from accident to arrival at the initial local ICU was approximately 2.9 hours (range $0.5-9$ hours). All children were intubated on site or at the primary hospital. After arriving at our NICU they received ICP monitoring, either by intraparenchymal (Codman; $n=17$ ) or by intraventricular catheter (Smiths Medical; $\mathrm{n}=11$ ). As shown in Table 2,3 children were operated on using unilateral hemicraniectomy, 2 before thiopental onset (patients 15 and 17) due to unilateral diffuse contusions causing midline shift, and 1 during thiopental treatment (patient 14). Patient 19 developed a small frontal postoperative intracerebral hematoma after an intraparenchymal pressure-monitoring device was inserted at day 1 , but at 11 days after trauma this patient had bifrontal craniectomies due to a sudden late expansion of this hematoma and diffuse edema causing a prolonged barbiturate coma. Patient 21 underwent bifrontal craniectomy 2 days after barbiturate coma discontinuation. Five other children (patients 4, 9-11, and 13) had mass lesions evacuated prior to thiopental administration. Patient 8 developed a frontal intracerebral hematoma 7 days after trauma, below a conservatively treated impression fracture. This was surgically evacuated before onset of barbiturate coma.

The median time period from trauma to onset of thiopental treatment was 46 hours (range 4.7-197.5 hours). Nineteen children were treated with intravenous thiopental and received a median bolus at initiation of $5.5 \mathrm{mg} / \mathrm{kg}$ (range $2.3-15.2 \mathrm{mg} / \mathrm{kg}$ ) followed by a median infusion rate of $5.5 \mathrm{mg} / \mathrm{kg} / \mathrm{hr}$ (range $4-8 \mathrm{mg} / \mathrm{kg} / \mathrm{hr}$ ). Median duration of barbiturate coma infusion was 107 hours (range 25-329 hours). Two children received thiopental as suppositories and had a mean bolus dose of $7.73 \mathrm{mg} / \mathrm{kg}$ followed by $1.43 \mathrm{mg} / \mathrm{kg} / \mathrm{hr}$ with suppositories at regular intervals. Median maximum serum thiopental for all children was 220 $\mu \mathrm{mol} / \mathrm{L}$ (range 30-460 $\mu \mathrm{mol} / \mathrm{L}$ ). Twelve children had continuous EEG recordings, 7 of whom (patients 3, 6, 10-12, 18, and 20; Tables 2 and 3) showed burst suppression during thiopental treatment, and 5 children (patients 4, 9, 15, 16, and 19; Tables 2 and 3) showed generalized slowing.

\section{Complications}

Blood gases were continuously followed (Table 4). Dif- 


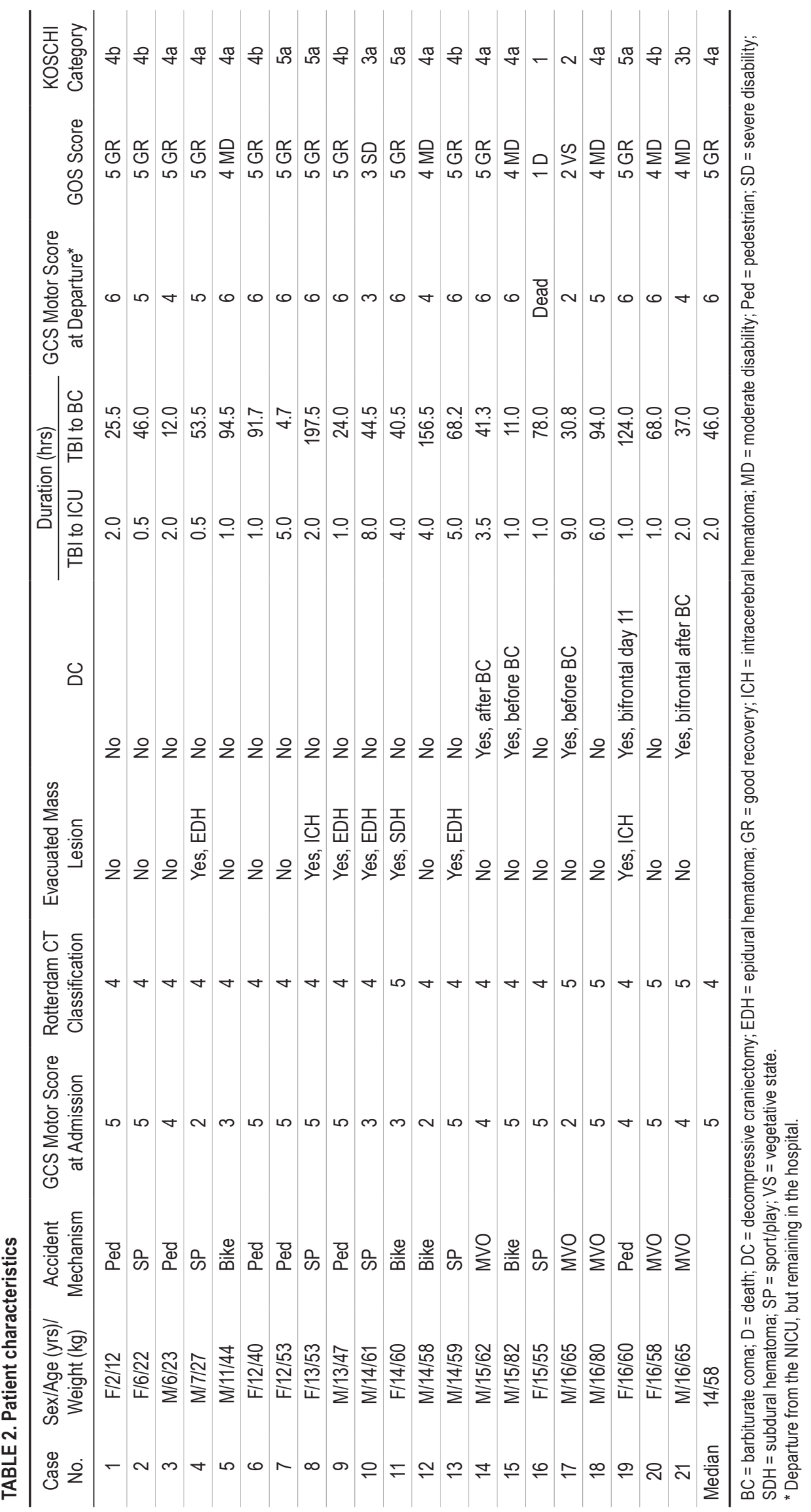




\begin{tabular}{|c|c|c|c|c|c|c|c|c|c|}
\hline \multirow[b]{2}{*}{ Case No. } & \multirow[b]{2}{*}{ BC Duration (hrs) } & \multirow{2}{*}{$\begin{array}{c}\text { Max Serum } \\
\text { Thiopental } \\
(\mu \mathrm{mol} / \mathrm{L})\end{array}$} & \multirow{2}{*}{$\begin{array}{c}\text { ICP >20 } \\
(\% \text { GMT })\end{array}$} & \multirow{2}{*}{$\begin{array}{c}\text { ICP >25 } \\
(\% \mathrm{GMT})\end{array}$} & \multicolumn{3}{|c|}{ Mean $(\mathrm{mm} \mathrm{Hg})$} & \multirow{2}{*}{$\begin{array}{l}\text { MAP <60 } \\
(\% \text { GMT })\end{array}$} & \multirow{2}{*}{$\begin{array}{l}\mathrm{MAP}<50 \\
(\% \mathrm{GMT}\end{array}$} \\
\hline & & & & & $\mathrm{ICP}$ & CPP & MAP & & \\
\hline $1^{*}$ & 107.0 & 30 & 10.0 & 1.4 & 15 & 54 & 68 & 13.4 & 0.0 \\
\hline $2^{*}$ & 187.5 & 130 & 17.2 & 7.5 & 15 & 55 & 70 & 6.3 & 0.0 \\
\hline $3^{*}$ & 74.0 & 350 & 5.7 & 0.0 & 14 & 48 & 62 & 35.2 & 0.0 \\
\hline 4 & 158.5 & 160 & 22.7 & 3.3 & 19 & 59 & 77 & 0.7 & 0.0 \\
\hline 5 & 70.7 & 190 & 7.7 & 3.2 & 15 & 64 & 79 & 0.0 & 0.0 \\
\hline 6 & 70.7 & 150 & 42.7 & 4.2 & 17 & 51 & 67 & 3.4 & 0.0 \\
\hline 7 & 109.6 & 240 & 23.6 & 6.7 & 17 & 58 & 75 & 0.1 & 0.0 \\
\hline 8 & 121.0 & 230 & 0.4 & 0.1 & 10 & 75 & 84 & 0.0 & 0.0 \\
\hline 9 & 118.5 & 370 & 7.1 & 0.8 & 15 & 63 & 78 & 0.0 & 0.0 \\
\hline 10 & 114.0 & 400 & 13.0 & 0.3 & 18 & 59 & 77 & 0.8 & 0.0 \\
\hline 11 & 166.5 & 460 & 15.3 & 1.7 & 17 & 64 & 81 & 0.9 & 0.0 \\
\hline 12 & 75.0 & 240 & 14.6 & 3.7 & 15 & 64 & 78 & 0.9 & 0.0 \\
\hline 13 & 96.3 & 220 & 4.8 & 0.3 & 15 & 61 & 75 & 2.1 & 0.0 \\
\hline 14 & 129.0 & 400 & 9.1 & 1.0 & 15 & 65 & 80 & 0.0 & 0.0 \\
\hline 15 & 99.0 & 200 & 0.5 & 0.0 & 13 & 78 & 91 & 0.0 & 0.0 \\
\hline 16 & 25.0 & 90 & 31.1 & 4.3 & 18 & 57 & 73 & 15.4 & 8.4 \\
\hline 17 & 50.8 & 140 & 30.7 & 4.6 & 16 & 60 & 75 & 0.9 & 0.0 \\
\hline 18 & 170.5 & 300 & 6.1 & 2.2 & 16 & 62 & 78 & 0.0 & 0.0 \\
\hline 19 & 329.0 & 220 & 27.1 & 9.2 & 17 & 68 & 85 & 0.3 & 0.0 \\
\hline 20 & 66.0 & 140 & 10.6 & 2.5 & 15 & 64 & 78 & 0.2 & 0.0 \\
\hline 21 & 41.0 & 290 & 28.1 & 3.7 & 18 & 56 & 74 & 0.4 & 0.0 \\
\hline Median & 107.0 & 220 & 13.0 & 2.5 & 15 & 61 & 77 & 0.7 & 0.0 \\
\hline
\end{tabular}

* Hourly values recorded.

ficulties were observed in patient 17 (Table 4), who had a maximum sodium level of $170 \mathrm{mmol} / \mathrm{L}$ and a minimum potassium level of $1.6 \mathrm{mmol} / \mathrm{L}$. At initiation of barbiturate coma the median sodium concentration was $141 \mathrm{mmol} / \mathrm{L}$ (range 132-148 $\mathrm{mmol} / \mathrm{L}$ ) and was above $140 \mathrm{mmol} / \mathrm{L}$ in all patients, except patients 5 and 13 who had $132 \mathrm{mmol} / \mathrm{L}$ due to salt-wasting syndrome and showed daily sodium losses in urine of $>400 \mathrm{mmol} /$ day. In patients 8 and 9 , serum sodium was only temporarily lower at initiation of barbiturate coma. Blood samples did not show any clinically significant renal dysfunction or hepatocellular toxicity, except transiently in one patient (patient 10, Table 4). All of the parameters in Table 4 normalized by the end of the NICU period. All children required inotropic infusions during barbiturate coma using noradrenaline or dobutamine at continuously adjusted levels to maintain sufficient mean arterial pressure (MAP) and prevent hypotension, and thereby also maintaining sufficient CPP. No hypotensive episodes with MAP $<50 \mathrm{~mm} \mathrm{Hg}$ were recorded during the barbiturate coma treatment (Table 3), except in patient 16 (described below).

Another complication observed during thiopental treatment was respiratory infections. Seventeen children were diagnosed with ventilator-associated pneumonia (verified by pulmonary infiltrations on chest radiography) and treated with antibiotics. None of these children developed severe respiratory problems. One child with multitrauma developed peritonitis due to a perforated ulcer despite prophylaxis. Meningitis was not verified by CSF culture or analysis in any of the cases. Patient 16 (Tables 2 and 3) received high-dose cefuroxime prophylaxis due to extensive skull base fractures, but developed sepsis after 3 days from suspected meningeal focus, causing circulatory instability and requiring high-dose noradrenaline. This was followed by progressive multiorgan failure. Due to ICP problems, barbiturate coma was initiated later on the same day. Thiopental infusion continued for 25 hours with a maximum serum concentration of $90 \mu \mathrm{mol} / \mathrm{L}$, but was discontinued due to circulatory instability and cardiac arrest. The patient was resuscitated, but died 10 hours afterward, 5 days after trauma.

\section{Length of Stay}

The average length of stay at our NICU was 21 days (range 11-44 days). At discharge, 11 children had been extubated with a mean intubation period of 16 days (range 10-28 days) and 9 children had a tracheostomy due to insufficient neurological recovery, of whom 4 were still in need of mechanical ventilation.

\section{Neurological Outcome}

At the end of the NICU period most children showed neurological improvement (Table 2). When leaving the 
TABLE 4. Electrolytes, renal, and hepatocellular function

\begin{tabular}{|c|c|c|c|c|c|c|}
\hline Case No. & $\begin{array}{l}\text { Sodium Range } \\
(\mathrm{mmol} / \mathrm{L})\end{array}$ & $\begin{array}{l}\text { Potassium Range } \\
\qquad(\mathrm{mmol} / \mathrm{L})\end{array}$ & $\begin{array}{l}\text { Max Creatinine } \\
(\mu \mathrm{mol} / \mathrm{L})\end{array}$ & $\begin{array}{c}\text { Max Urea } \\
(\mathrm{mmol} / \mathrm{L})\end{array}$ & $\begin{array}{c}\text { Max ALAT } \\
(\mu k a t / L)\end{array}$ & $\begin{array}{c}\text { Max ASAT } \\
(\mu \mathrm{kat} / \mathrm{L})\end{array}$ \\
\hline 1 & $132-145$ & $3.1-4.2$ & 27 & 5.3 & 0.29 & 1.25 \\
\hline 2 & $134-140$ & $2.9-4.7$ & 36 & 6.0 & 3.21 & 3.82 \\
\hline 3 & $134-142$ & $3.1-3.5$ & 61 & 7.2 & 1.44 & 4.30 \\
\hline 4 & $132-144$ & $2.4-4.1$ & 77 & 4.0 & 1.33 & 3.93 \\
\hline 5 & $128-143$ & $3.1-4.0$ & 35 & 4.7 & 0.72 & 1.02 \\
\hline 6 & $136-144$ & $2.4-4.5$ & 86 & 14.8 & 1.13 & 2.94 \\
\hline 7 & $137-149$ & $3.1-5.1$ & 50 & 3.3 & 0.60 & 1.79 \\
\hline 8 & $136-145$ & $3.4-4.2$ & 53 & 6.5 & 0.41 & 0.81 \\
\hline 9 & $134-146$ & $3.2-4.4$ & 81 & 4.1 & 1.01 & 0.61 \\
\hline 10 & $132-151$ & $2.7-5.5$ & 278 & 29.0 & 2.49 & 2.14 \\
\hline 11 & $135-147$ & $2.7-5.3$ & 75 & 7.0 & 0.76 & 2.43 \\
\hline 12 & 133-152 & $2.8-4.6$ & 95 & 9.4 & 0.79 & 0.96 \\
\hline 13 & $132-145$ & $3.4-4.2$ & 56 & 7.8 & 0.38 & 0.93 \\
\hline 14 & $135-142$ & $3.2-4.5$ & 89 & 9.0 & 0.68 & 1.07 \\
\hline 15 & 132-142 & $3.1-3.9$ & 50 & 3.9 & 0.50 & 0.97 \\
\hline 16 & $136-146$ & $2.8-4.9$ & 65 & 2.0 & 0.27 & 1.24 \\
\hline 17 & $137-170$ & $1.6-5.3$ & 164 & 6.1 & 1.45 & 7.70 \\
\hline 18 & $141-149$ & $3.3-5.0$ & 96 & 11.0 & 2.01 & 1.43 \\
\hline 19 & $135-144$ & $2.4-4.0$ & 70 & 8.7 & 1.66 & 1.87 \\
\hline 20 & 144-152 & $2.5-4.0$ & 50 & 5.2 & 0.97 & 0.89 \\
\hline 21 & $148-168$ & $1.9-3.4$ & 85 & 6.1 & 0.86 & 2.12 \\
\hline
\end{tabular}

ALAT = alanine aminotransferase; ASAT = aspartate aminotransferase.

Reference values: creatinine 39-83 $\mu \mathrm{mol} / \mathrm{L}$, urea $2.7-7.1 \mathrm{mmol} / \mathrm{L}$, ALAT $<0.7 \mu \mathrm{kat} / \mathrm{L}$, ASAT $<0.7 \mu \mathrm{kat} / \mathrm{L}$.

NICU, the median GCS motor score was 6 compared to 5 at admission. Assessing recovery and outcome 1 year later, the median GOS score was 5, indicating good recovery (range 1-5). But the more specific KOSCHI scale (Fig. 1) gave a more modest score, with a median of $4 a$, indicating moderate disability (range 1-5a); 4 children with good outcome (KOSCHI 5a), 13 children with moderate disability (KOSCHI 4a and 4b), 2 children with severe disability (KOSCHI $3 \mathrm{a}$ and 3b, including patient 10 [Tables 2 and 3] due to tetraplegia caused by a cervical fracture and high medullary injury), and 1 child remained in a vegetative state (KOSCHI 2) and died 2 years after trauma. As described above, patient 16 died during the NICU period.

In the children who developed RICH, continuous ICP curve data showed escalation of disturbances in intracranial dynamics in the form of elevated ICP values, high amplitudes, and increasing number of A-waves prior to the addition of barbiturates. However, mean ICP was below 20 $\mathrm{mm} \mathrm{Hg}$. After initiation of thiopental treatment these ICP problems gradually improved. Examples of this are shown in Fig. 2. In Table 3 the percentage of ICP good monitoring time (GMT) above $20 \mathrm{~mm} \mathrm{Hg}$ and $25 \mathrm{~mm} \mathrm{Hg}$ is shown.

\section{Discussion}

In the NICU in Uppsala, 21 of 60 children $(\leq 16$ years of age) with severe TBI developed RICH and were subsequently treated with barbiturate coma. These 21 children had a median GCS score of 7 on admission to the NICU and a median Rotterdam CT score of 4 at first CT scan. At 1-year follow-up, the median GOS score was 5 and median KOSCHI score was 4a. Thus, in this subgroup of children with severe TBI and RICH, it is possible to achieve good outcomes. The monosedative, high-dose barbiturate coma treatment appeared to be an effective approach in children with RICH when used in the modern and structured NICU setting and was associated with minor complications that could be managed.

From a historical perspective, uncertainty about effects on outcome and drug-related complications have led to a restrictive attitude about the use of this treatment in many centers..$^{15,27,29}$ However, the low complication rates and relatively favorable outcome results found in this study indicate that barbiturates have a place in the management of RICH in children. This is also supported by the study of Mellion et al. in 2013, ${ }^{22}$ who presented a series of children also treated in a modern NICU setting using pentobarbital with comparable results to ours. In both studies, complications related to the barbiturate treatment (i.e., infection, hepatocellular, and cardiovascular) were not the cause of any serious medical events. In the past these types of complications contributed to increased mortality, which negatively influenced outcome. ${ }^{10}$ Thus, a modern NICU with multimodality monitoring, maximal focus on avoiding secondary insults, and improved cardiopulmonary care probably provides better conditions for successful barbiturate treatment.

The 21 children included in this study developed RICH 


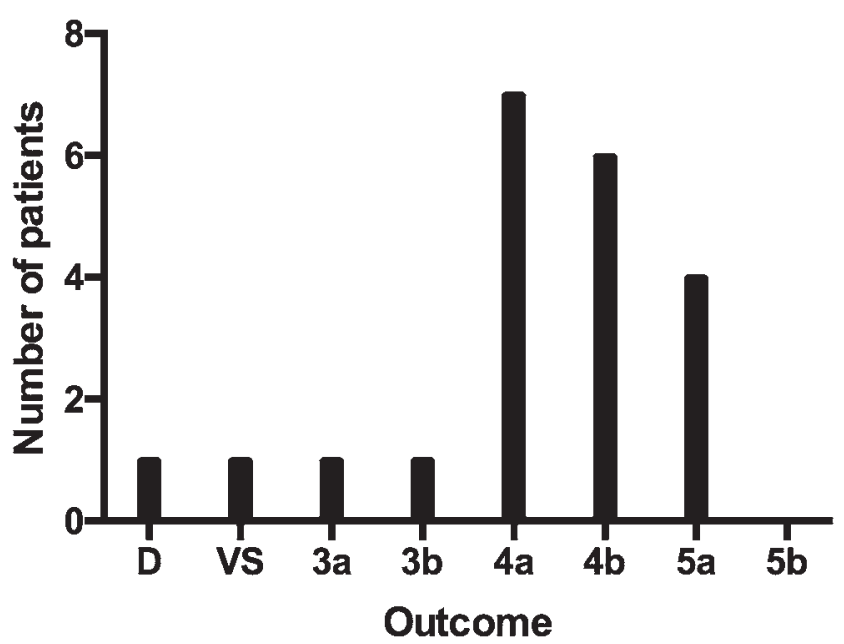

FIG. 1. Graph of outcome 12 months after TBI according to the KOSCHI classification $(n=21)$ : $D=$ death; $V S=$ vegetative state; 3 = severe disability; 4 = moderate disability; 5 = good recovery.

and therefore received barbiturate coma treatment, but 5 underwent decompressive craniectomy. However, 16 of these patients did not need decompressive craniectomy to control ICP. Compared to the other 39 children with severe TBI who did not develop RICH and did not receive barbiturates, 4 underwent decompressive craniectomy, all due to midline shift. The study does not compare barbiturate coma to decompressive craniectomy, but shows that in many cases RICH can be handled and controlled using barbiturate coma, thereby avoiding the surgical procedure of decompressive craniectomy and its potential complications.

The percentage of responders in this study is higher than that reported by most other groups. . $^{917,20-22,28,37}$ A possible explanation for this could be different approaches in management. The patients in this study were treated according to protocols based on Swedish ICU traditions that were more ICP-oriented than traditional CPP-oriented protocols. ${ }^{30}$ We have reported earlier that this type of strategy can be advantageous when patients have disturbed pressure autoregulation of cerebral blood flow and $\mathrm{RICH} .{ }^{1,7,13} \mathrm{Be}-$ cause there is no need to increase blood pressure to excessive levels, this decreases the risk of raising ICP as a result of increased cerebral blood volume due to a blood-pressure elevation in pressure-passive patients. Lower blood pressure also probably lowers the risk of cerebral vasogenic edema associated with blood-brain barrier breakage.

Another probable effect of the ICP-oriented therapy was that no patient developed severe pulmonary edema. In CPP-based treatment this is a common problem, ${ }^{5}$ which is even worse if the patient is receiving barbiturate treatment. These complications are believed to be related to the fluid and inotropic treatment that is given to achieve sufficient CPP levels. This type of physiological challenge is not required in ICP-oriented therapy. Seventeen (81\%) of the 21 patients in this study developed ventilator-associated pneumonia compared to 11 (28\%) of the 39 remaining children with severe TBI who were not treated with barbiturate coma at our NICU during the same period (data not illustrated). The high incidence of pneumonia in the

ICP before and after $\mathrm{BC}$ in patient 18
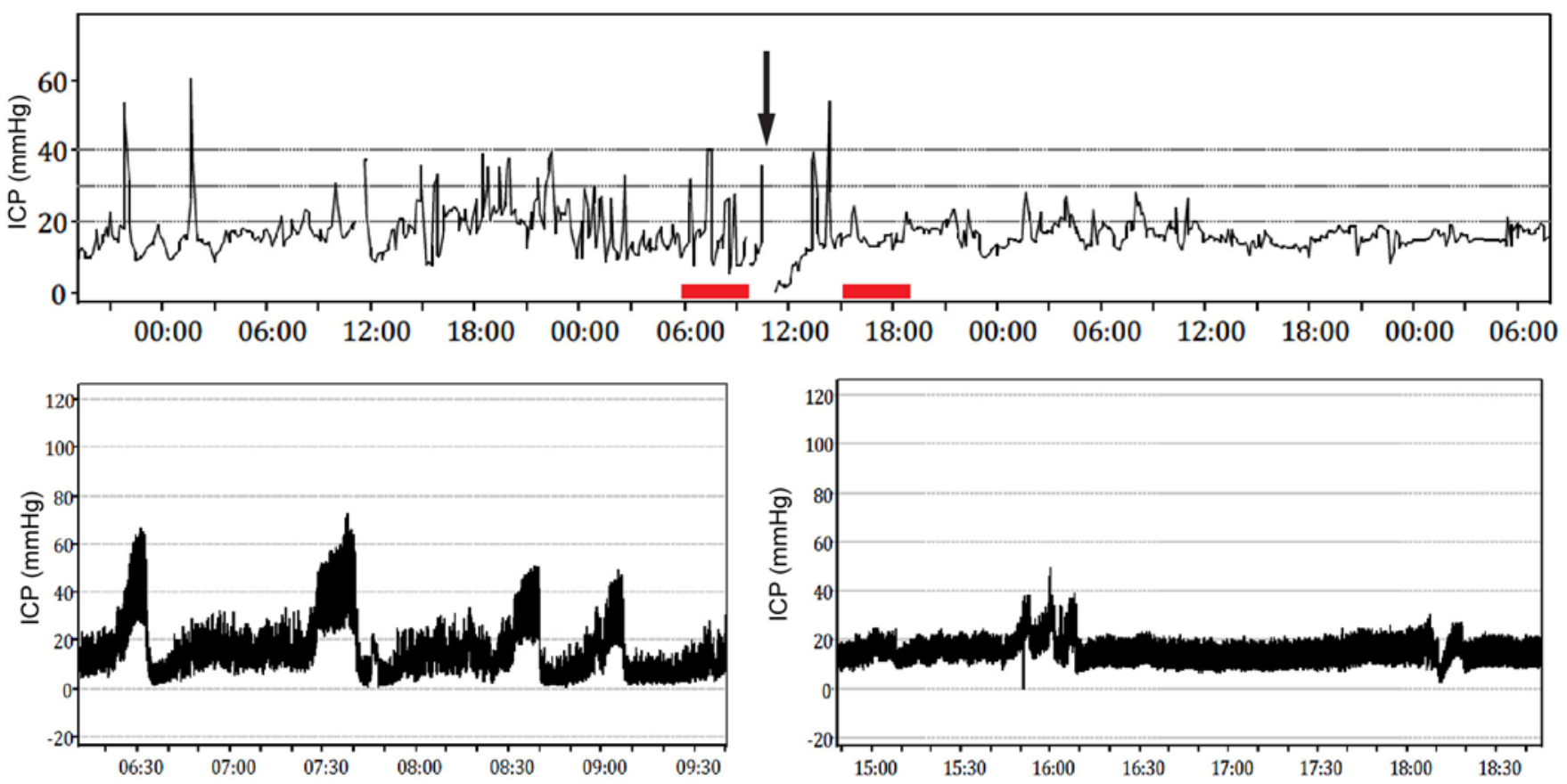

FIG. 2. Case 18. ICP before and after onset of barbiturates (BC) at 11:00 (arrow). Marked time periods from the graph in the upper part of the figure (red bars) are highlighted below and show "classic" Lundberg presentation of ICP waveform data, with A-waves before onset of barbiturates (lower left) and a smoother ICP curve with lower amplitudes and no A-waves after onset of barbiturates (lower right). Figure is available in color online only. 
barbiturate coma-treated group was probably a side effect of the barbiturate coma because such treatment causes a general depression of the immune response $\mathrm{e}^{34}$ as well as affecting the lungs' capacity to handle fluid secretion. However, these pulmonary complications did not lead to severe respiratory distress. Reducing the risk of pulmonary edema probably also reduces the severity of a pulmonary infection.

The child with RICH and sepsis (patient 16, Tables 2 and 3) had unstable circulation. Because of the circulatory instability, surgery using decompressive hemicraniectomy was deemed impossible and barbiturates were added as a last chance option.

There are inherent limitations in the present study. It is based on a retrospective cohort, a small number of patients, and there is no comparative patient group. However, the results are interesting because of the limited number of published results on the use of barbiturates in children with RICH in a modern NICU treatment environment. ${ }^{16,22}$ In the newly updated third edition of the Guidelines for the Management of Pediatric Severe Traumatic Brain Injury, ${ }^{16}$ the chapter content on barbiturate coma treatment is unchanged. The present evidence for barbiturate treatment in children is still very weak. To our knowledge, only one study has directly addressed the topic and reported results of barbiturate coma in children. ${ }^{22}$ Considering the almost complete absence of reported results of thiopental coma treatment in children, our study provides important additional knowledge. Our study supports the idea that RICH can be managed using barbiturate coma without severe side effects and with an overall good outcome in a modern ICU setting. The study also gives an indication of the increased safety that the modern ICU provides even if it is difficult to identify any specific factor of importance. Instead, protocol-based treatment strategies, imaging, computer-based multimodality monitoring, and a focus on avoiding all kinds of secondary insults have all together probably contributed to this level of safety. Another important factor in achieving this level of safety, in an advanced treatment such as barbiturate coma, is to have a high competence level among all types of staff specialized in neurointensive care so that implementation of secondary insult prevention and standardized care can be maintained. ${ }^{10,11}$

\section{Conclusions}

The results of this study indicate that monosedative high-dose barbiturate coma, when used in a modern NICU, can be an effective means of lowering ICP without causing concomitant severe side effects in children with RICH. This treatment strategy in children with RICH was compatible with good long-term outcome.

\section{References}

1. Adelson PD, Srinivas R, Chang Y, Bell M, Kochanek PM: Cerebrovascular response in children following severe traumatic brain injury. Childs Nerv Syst 27:1465-1476, 2011

2. Almaas R, Saugstad OD, Pleasure D, Rootwelt T: Effect of barbiturates on hydroxyl radicals, lipid peroxidation, and hypoxic cell death in human NT2-N neurons. Anesthesiology 92:764-774, 2000

3. Calvert S, Miller HE, Curran A, Hameed B, McCarter R,
Edwards RJ, et al: The King's Outcome Scale for Childhood Head Injury and injury severity and outcome measures in children with traumatic brain injury. Dev Med Child Neurol 50:426-431, 2008

4. Cole DJ, Cross LM, Drummond JC, Patel PM, Jacobsen WK: Thiopentone and methohexital, but not pentobarbitone, reduce early focal cerebral ischemic injury in rats. Can J Anaesth 48:807-814, 2001

5. Contant CF, Valadka AB, Gopinath SP, Hannay HJ, Robertson CS: Adult respiratory distress syndrome: a complication of induced hypertension after severe head injury. J Neurosurg 95:560-568, 2001

6. Crouchman M, Rossiter L, Colaco T, Forsyth R: A practical outcome scale for paediatric head injury. Arch Dis Child 84:120-124, 2001

7. Czosnyka M, Smielewski P, Piechnik S, Steiner LA, Pickard JD: Cerebral autoregulation following head injury. J Neurosurg 95:756-763, 2001

8. Drummond JC, Patel PM, Cole DJ: Cerebral protection: are all barbiturates created equal? Anesthesiology 85:15041505,1996

9. Eisenberg HM, Frankowski RF, Contant CF, Marshall LF, Walker MD: High-dose barbiturate control of elevated intracranial pressure in patients with severe head injury. J Neurosurg 69:15-23, 1988

10. Elf K, Nilsson P, Enblad P: Outcome after traumatic brain injury improved by an organized secondary insult program and standardized neurointensive care. Crit Care Med 30:2129-2134, 2002

11. Elf K, Nilsson P, Ronne-Engström E, Howells T, Enblad P: Cerebral perfusion pressure between 50 and $60 \mathrm{~mm} \mathrm{Hg}$ may be beneficial in head-injured patients: a computerized secondary insult monitoring study. Neurosurgery 56:962-971, 2005

12. Howells T, Elf K, Jones PA, Ronne-Engström E, Piper I, Nilsson $\mathrm{P}$, et al: Pressure reactivity as a guide in the treatment of cerebral perfusion pressure in patients with brain trauma. $\mathbf{J}$ Neurosurg 102:311-317, 2005

13. Howells TP, Piper IR, Souter MJ, Souter MJ, Miller JD: Design of a research database for the study of secondary insults following head injury. J Neurotrauma 12:471-472, 1995 (Abstract)

14. Jennett B, Bond M: Assessment of outcome after severe brain damage. Lancet 1:480-484, 1975

15. Kasoff SS, Lansen TA, Holder D, Filippo JS: Aggressive physiologic monitoring of pediatric head trauma patients with elevated intracranial pressure. Pediatr Neurosci 14:241-249, 1988

16. Kochanek PM, Tasker RC, Carney N, Totten AM, David AP, Selden NR, et al: Guidelines for the Management of Pediatric Severe Traumatic Brain Injury, Third Edition: Update of the Brain Trauma Foundation Guidelines. Pediatr Crit Care Med 20 (1 Suppl):S1-S82, 2019

17. Lee MW, Deppe SA, Sipperly ME, Barrette RR, Thompson DR: The efficacy of barbiturate coma in the management of uncontrolled intracranial hypertension following neurosurgical trauma. J Neurotrauma 11:325-331, 1994

18. Liesemer K, Riva-Cambrin J, Bennett KS, Bratton SL, Tran $\mathrm{H}$, Metzger RR, et al: Use of Rotterdam CT scores for mortality risk stratification in children with traumatic brain injury. Pediatr Crit Care Med 15:554-562, 2014

19. Maas AI, Hukkelhoven CW, Marshall LF, Steyerberg EW: Prediction of outcome in traumatic brain injury with computed tomographic characteristics: a comparison between the computed tomographic classification and combinations of computed tomographic predictors. Neurosurgery 57:11731182,2005

20. Marshall GT, James RF, Landman MP, O’Neill PJ, Cotton BA, Hansen EN, et al: Pentobarbital coma for refractory 
intra-cranial hypertension after severe traumatic brain injury: mortality predictions and one-year outcomes in 55 patients. $\mathbf{J}$ Trauma 69:275-283, 2010

21. Marshall LF, Smith RW, Shapiro HM: The outcome with aggressive treatment in severe head injuries. Part II: acute and chronic barbiturate administration in the management of head injury. J Neurosurg 50:26-30, 1979

22. Mellion SA, Bennett KS, Ellsworth GL, Moore K, RivaCambrin J, Metzger RR, et al: High-dose barbiturates for refractory intracranial hypertension in children with severe traumatic brain injury. Pediatr Crit Care Med 14:239-247, 2013

23. Nyholm L, Lewén A, Fröjd C, Howells T, Nilsson P, Enblad $\mathrm{P}$ : The use of nurse checklists in a bedside computer-based information system to focus on avoiding secondary insults in neurointensive care. ISRN Neurol 2012:903954, 2012

24. Orliaguet GA, Meyer PG, Baugnon T: Management of critically ill children with traumatic brain injury. Paediatr Anaesth 18:455-461, 2008

25. Paget SP, Beath AW, Barnes EH, Waugh MC: Use of the King's Outcome Scale for Childhood Head Injury in the evaluation of outcome in childhood traumatic brain injury. Dev Neurorehabil 15:171-177, 2012

26. Pérez-Bárcena J, Llompart-Pou JA, Homar J, Abadal JM, Raurich JM, Frontera G, et al: Pentobarbital versus thiopental in the treatment of refractory intracranial hypertension in patients with traumatic brain injury: a randomized controlled trial. Crit Care 12:R112, 2008

27. Pittman T, Bucholz R, Williams D: Efficacy of barbiturates in the treatment of resistant intracranial hypertension in severely head-injured children. Pediatr Neurosci 15:13-17, 1989

28. Rea GL, Rockswold GL: Barbiturate therapy in uncontrolled intracranial hypertension. Neurosurgery 12:401-404, 1983

29. Roberts I, Sydenham E: Barbiturates for acute traumatic brain injury. Cochrane Database Syst Rev 12:CD000033, 2012

30. Rosner MJ, Rosner SD, Johnson AH: Cerebral perfusion pressure: management protocol and clinical results. J Neurosurg 83:949-962, 1995

31. Sato M, Tanaka S, Suzuki K, Kohama A, Fujii C: Complications associated with barbiturate therapy. Resuscitation 17:233-241, 1989

32. Schalén W, Messeter K, Nordström CH: Complications and side effects during thiopentone therapy in patients with severe head injuries. Acta Anaesthesiol Scand 36:369-377, 1992
33. Shibuta S, Kosaka J, Mashimo T, Fukuda Y, Yoshiya I: Nitric oxide-induced cytotoxicity attenuation by thiopentone sodium but not pentobarbitone sodium in primary brain cultures. Br J Pharmacol 124:804-810, 1998

34. Stover JF, Stocker R: Barbiturate coma may promote reversible bone marrow suppression in patients with severe isolated traumatic brain injury. Eur J Clin Pharmacol 54:529-534, 1998

35. Sundstrøm T, Sollid S, Wentzel-Larsen T, Wester K: Head injury mortality in the Nordic countries. J Neurotrauma 24:147-153, 2007

36. Swedish National Board of Health and Welfare: [Causes of Death 2014.] Stockholm: Official Statistics of Sweden, 2015 (Swedish) (https://www.socialstyrelsen.se/globalassets/ sharepoint-dokument/artikelkatalog/statistik/2015-8-1.pdf) [Accessed October 25, 2019]

37. Thomale UW, Graetz D, Vajkoczy P, Sarrafzadeh AS: Severe traumatic brain injury in children-a single center experience regarding therapy and long-term outcome. Childs Nerv Syst 26:1563-1573, 2010

38. Thurman DJ: The epidemiology of traumatic brain injury in children and youths: a review of research since 1990. J Child Neurol 31:20-27, 2016

\section{Disclosures}

The authors report no conflict of interest concerning the materials or methods used in this study or the findings specified in this paper.

\section{Author Contributions}

Conception and design: Velle, Enblad, Nilsson. Acquisition of data: Velle, Howells. Analysis and interpretation of data: Velle, Lewén, Enblad, Nilsson. Drafting the article: Velle, Nilsson. Critically revising the article: Velle, Lewén, Enblad, Nilsson. Reviewed submitted version of manuscript: all authors. Statistical analysis: Howells. Administrative/technical/material support: Howells. Study supervision: Enblad.

\section{Correspondence}

Fartein Velle: Uppsala University Hospital, Uppsala, Sweden. fartein.velle@neuro.uu.se; fartein.velle@akademiska.se. 